\title{
Share and share alike
}

\author{
Ian Yeoman ${ }^{1}$
}

(C) Springer Nature Limited 2018

The shared economy is a relative new phenomena, it is changing distribution models especially in the hotel sector. The 'sharing economy' has emerged in the past several years as a new model for offering a variety of goods and services, often in a peer-to-peer environment. As the sharing economy grows, it presents both threats and opportunities for revenue management. A sharing economy focuses on access to resources-products and servicesrather than direct ownership or control of those resources. Some forms of non-ownership have long existed. People may rent rather than buy their living quarters, or lease rather than buy their vehicles. The sharing economy has changed things without doubt.

Oskam and explore the shared economy, with one of the first papers taking a Revenue Management and Pricing perspective which is described as disruptive. Oskam and colleagues explore Airbnb's host "professionalization", building on the strategic management literature showing efficient pricing behaviour to be the result of an acquired capability required to interpret complex and incomplete information. Through an analysis of 11,264,907 daily observations from 32,815 units, it finds that hosts who adjust their prices more frequently outperform others in RevPAR, ADR, and occupancy. Findings included hosts who adjust their prices more frequently, upward and/or downward - controlled for variations in the level of prices, the number of distinct prices, as well as the number of properties per host and the number of observations-outperform other hosts both in RevPAR, ADR, and occupancy. In addition, properties with a higher mean negative

\footnotetext{
Ian Yeoman

ian.yeoman@vuw.ac.nz

1 Victoria University of Wellington, Wellington, New Zealand
}

price change have a lower RevPAR and ADR, and properties with a higher mean positive price change have a higher ADR. Meaning, to do this dynamic pricing behaviour is knowing when and how to adjust prices, an acquired capability essential to the interpretation of complex and incomplete information.

Gupta and colleagues explore the pricing decisions of car aggregation platforms in the sharing economy. They build a system dynamics model of a ride sharing platform in a developing country that endogenizes the growth of the platform in the presence of stickiness of the asset provider, since platform growth can occur only through new investments in assets that have limited utility outside the platform. The contribution of the paper lies in a nuanced understanding of pricing and incentive decisions in twosided markets, which exhibit cross-group positive externalities and within-group negative externalities and emphasize that the long-term objectives of the platform owner may differ from those of the asset owners.

The cruise industry has experienced steadily increasing growth in the recent years according a research paper by Rius. The aim of this research is to identify the pricing strategies at global and local levels in the cruise industry using an analysis of some cruise websites, the creation of an extensive database in order to build a hedonic model that enables the identification of marketing strategies, and interviews with professionals of the sector. Reported results include that cruise companies have too analyse the impact of moving towards other destinations or to set in the same zone, in spite of the fact that they are conscious of the reduction in demand and prices. Cruise companies use a great variety of pricing strategies, some of which are related to the services provided in the ships, the destinations and ports of call, the number of nights of the itinerary, or by segmenting the market, for example, according to the 
customers' willingness to pay. Thus, Cruise industry can be considered an advanced activity in the tourism sector, both in the development of marketing strategies, especially pricing and RM, and in the use of advanced technologies, facilitating cruise lines to increase revenues, profits, and efficiency.

Cox delves into the world of RM and training noting that existing approaches to revenue management training have been criticized for producing analysts who have a good understanding of revenue systems, but less capability to make strategic decisions and communicate across a range of stakeholders. What Cox discovers is that simulation- based revenue management training delivers a well-rounded set of learning outcomes. Altarawneh aims to provide a feasible and practical tool pricing for decision makers in the energy and electricity sectors using a fuzzy logic technique to help Energy and Minerals Regulatory Commission of Jordan to assign a fair and dynamic sale price for electricity, based on two categories of electricity consumption (low and high). Finally, Liozu's paper brings some laughter, humour and fun to pricing. Its definitely the best ever paper published by this journal in the last seventeen years. 